\title{
CORRELAÇÕES ENTRE VISÕES DE MATEMÁTICA E DE RESOLUÇÃO DE PROBLEMAS DE PROFESSORAS QUE ENSINAM MATEMÁTICA
}

\section{CORRELATION BETWEEN MATHEMATICS AND PROBLEM SOLVING VISIONS OF TEACHERS WHO TEACH MATHEMATICS}

\author{
Thiarla Xavier Dal-Cin Zanon \\ Instituto Federal do Espírito Santo - câmpus Cachoeiro do Itapemirim \\ E-mail: prof.thiarla@hotmail.com
}

\section{Vânia Maria Pereira dos Santos-Wagner \\ Universidade Federal do Espírito Santo \\ E-mail: profvaniasantoswagner@gmail.com}

\section{Resumo}

O objetivo desse artigo é analisar correlações entre visões de matemática e de resolução de problemas de três professoras que ensinam Matemática nos anos iniciais do Ensino Fundamental e que se encontram em períodos diferentes de experiência docente. Essas professoras participaram de oficinas de formação continuada de Matemática desenvolvidas colaborativamente entre pesquisadoras e professoras. A partir dos dados de uma pesquisa qualitativa, observamos também se essas visões de Matemática e resolução de problemas interferem/influenciam mutuamente nos processos de ensinar, aprender e avaliar em Matemática. Analisamos as informações e dados a partir da literatura estudada sobre estes assuntos. Notamos que as correlações se evidenciam na interferência/influência que a visão de Matemática exerce sobre a visão de resolução de problemas.

Palavras-chave: visões e concepções de Matemática. visões de resolução de problemas. formação continuada. professoras que ensinam matemática.

\section{Abstract}

The goal of this article is to analyze correlations between the sights on problem solving and Mathematics of three Math teachers who work in the early years of Ensino Fundamental and are in different moments of their career. The teachers took part in Teacher's Continued Education workshops, which were collaboratively developed by researchers and teachers. From the qualitative research data, we also observed that their sight on Mathematics and problem solving interfere/influence mutually in the way they teach Mathematics, learning and assessment processes. We analyze the information and data from the studied literature concerning these topics. We noticed that the correlation is evident in the interference/ influence that the sight on Mathematics has over the sight on problem solving.

Palavras-chave: Mathematics visions and conceptions. problem solving visions. continuing teacher education. teachers who teach Mathematics. 


\section{INTRODUÇÃO}

Cotidianamente vemos em noticiários a relevância e o impacto que os números causam na vida das pessoas. Na maioria das vezes, eles são usados para apontarem resultados de avaliações, como, por exemplo, o Programa Internacional de Avaliação de Estudantes - PISA (Programme for International Student Assessment), o Exame Nacional do Ensino Médio ENEM e demais avaliações externas, ou para mostrar o impacto de grandezas em outros acontecimentos que afetem direta ou indiretamente as decisões de seus usuários. Vivemos em um mundo rodeado por números e saber compreendê-los tem se mostrado uma competência útil ao exercício da cidadania. Tal fato tem desencadeado preocupações com o ensino de Matemática na Educação Básica. Consideramos que há preocupações didáticas, pedagógicas e sociais pensadas a partir daquilo que se ensina em matemática, como se aprende, como se avalia e quais usos são feitos desse conhecimento matemático. E que também há preocupações com o professor que ensina essa disciplina na escola, com sua formação seja ela inicial ou continuada, uma vez que ele é o responsável por mobilizar o processo de ensino-aprendizagem-avaliação em Matemática dentro da sala de aula.

Diante desse contexto, observamos que há significativa produção acadêmica em Educação Matemática que discute a formação de professores de Matemática, sobretudo daqueles que ensinam Matemática. Para isso, basta consultarmos, por exemplo, a revista Zetetiké para termos um breve panorama das publicações a esse respeito. Algumas pesquisas demonstram a complexidade que envolve a formação docente e suas especificidades para ensinar, aprender e avaliar em Matemática, como é o caso da pesquisa de Silva (2009). Tais especificidades denotam que as preocupações recentes centram-se na forma como os professores estruturam e desenvolvem seus conhecimentos e como, a partir deles, constroem e organizam novos referenciais teóricos e metodológicos para ensinar, aprender e avaliar em Matemática.

Assim sendo, retrata-se nesse artigo um recorte de uma pesquisa de mestrado realizada com professoras que ensinam Matemática nos anos iniciais do Ensino Fundamental em escolas 
situadas no interior do município de Castelo/ES no ano de 2010. Nele, analisa-se as visões de Matemática e de resolução de problemas, bem como suas possíveis correlações, exibidas por três professoras que participaram de ações de formação continuada desenvolvidas na pesquisa realizada por Zanon (2011). Dessa forma, procura-se discorrer nesse texto sobre dois questionamentos: que correlações identificamos entre visões de Matemática e de resolução de problemas relatadas por professoras que ensinam Matemática em oficinas de formação continuada? Como observamos que essas visões interferem/influenciam mutuamente os processos de ensinar, aprender e avaliar em Matemática?

Nosso objetivo foi identificar correlações entre visões de Matemática e de resolução de problemas relatadas em oficinas de formação continuada por professoras que ensinam Matemática e se encontram em períodos diferentes de experiência docente. Além de observarmos também se essas visões interferem/influenciam mutuamente nos processos de ensinar, aprender e avaliar em matemática. Para compreender essas visões e as possíveis correlações entre elas, propusemos oficinas de formação continuada desenvolvidas com professoras em exercício. Valemo-nos das "vozes" delas, das coletividades e das redes que estabeleciam nos cotidianos das escolas. E, assim, programamos as oficinas junto às professoras, ou seja, com elas, possibilitando uma reflexão crítica entre a coletividade. Partimos do princípio de que a forma como se compreende a Matemática influencia o desenvolvimento da prática do professor, bem como sua predisposição para ensinar, aprender e avaliar em Matemática na Educação Básica (ERNEST, 1988, GÓMEZ CHACÓN, 2003; SANTOS, 1994, 1997; SILVA, 2009; THOMPSON, 1997/1984).

\section{ENQUADRAMENTO TEÓRICO}

Inicialmente, descrevemos as bases teóricas que fundamentaram nossa pesquisa e subsidiaram, a posteriori, a análise de dados e informações. Em seguida, tecemos um panorama do contexto da pesquisa. A pesquisa desenvolvida concatena-se à formação continuada, ao papel dos afetos na Matemática e à resolução de problemas como uma 
metodologia de ensino, de aprendizagem e de avaliação em Matemática. Entende-se a formação continuada como aquela que acontece após a formação inicial num ato contínuo desenvolvido ao longo da vida profissional. Subjacente a esta concepção, está o conceito de desenvolvimento profissional, uma vez que apreciamos propostas de formação continuada desenvolvidas em colaboração, pois potencializam a reflexão coletiva e crítica da prática cotidiana da sala de aula. Corroboramos assim com Gatti e Barreto (2009) quando apontam que o processo de formação passa então a ser definido como

um movimento orientado a responder aos diversos desafios que se sucedem no que se poderia identificar como diferentes fases de vida profissional: o início da carreira, o processo de desenvolvimento e os tempos mais avançados em que o professor consolida sua experiência profissional (p. 203).

Ernest (1988), Thompson (1997/1984), Santos (1994, 1997) e Gómez Chacón (2003) investigaram a existência ou não de relações entre concepções de professores e as práticas que eles desenvolvem em sala de aula. Esses autores apontam que o ensino, a aprendizagem e a avaliação em Matemática, as escolhas pedagógicas, a definição de objetivos e conteúdos a abordar, e as formas de avaliação estão intimamente ligadas às concepções dos professores sobre a Matemática. Ao lermos atentamente documentos oficiais como os Parâmetros Curriculares Nacionais [PCN] (BRASIL, 1997) de Matemática para os anos iniciais, parece-nos que estes documentos também trazem implicitamente essas ideias.

Thompson (1997/1984) pontuou alguns padrões de comportamento e visões sobre a Matemática manifestadas na prática pedagógica de professores a partir de observação e análise de alguns casos de professores a partir de diferentes abordagens didáticas. Valorizou esse estudo por acreditar que:

Os professores desenvolvem padrões de comportamento característicos de sua prática pedagógica. Em alguns casos, esses padrões podem ser 
manifestações de noções, crenças e preferências, conscientemente sustentadas, que agem como forças motrizes na formação do seu comportamento. Em outros casos, as forças motrizes podem ser crenças ou intuições, inconscientemente sustentadas, que podem ter evoluído fora da experiência do professor (1997, p. 12).

Para Ernest (1988) é importante conhecer crenças e concepções de professores sobre a natureza da Matemática e seu processo pedagógico. Assim, sinalizou que a Matemática pode ser entendida sob três distintas visões: (1) Matemática como um instrumento, (2) Matemática como corpo estático e unificado de conhecimento, e, (3) Matemática como um campo de criação humana em grande e constante expansão. Ou seja, para esse autor, na primeira visão alguns professores percebem Matemática e conhecimentos matemáticos como sendo instrumentos para serem usados na vida; na segunda visão identificam Matemática como conhecimento pronto, acabado, estático, quase como algo que existe para ser descoberto; e na terceira visão concebem a Matemática como sendo algo criado pelo homem, servindo para resolver e formular problemas. Assim, essas visões de Matemática, que os professores possuem mas nem sempre tomam consciência, os conduzem ao desempenho de uma prática particular de ensino.

Ernest (1991) discorre sobre a relação entre visão de Matemática e as implicações dessas na forma como o professor verá a resolução de problema. Escreve sobre a resolução de problemas na perspectiva do professor, e o faz por acreditar que os professores têm diferentes crenças sobre a natureza da Matemática e seu ensino e aprendizagem, que afetam fortemente suas práticas de sala de aula. Numa leitura atenta das ideias de Ernest (1991) apreendemos que um professor com uma visão absolutista da Matemática [visão de Matemática como um instrumento] exteriorizará a resolução de problemas como o desenvolvimento de tarefas rotineiras. As respostas aos problemas apresentadas serão sempre certas e determinadas. Nesse caso, Ernest (1991) diz que a resolução de problemas é, portanto, uma atividade que aparece após a transmissão de conteúdos matemáticos, e fornece os meios para aplicar conhecimentos e habilidades aprendidas anteriormente. Um 
professor com uma filosofia/visão absolutista progressiva da Matemática [visão de Matemática como corpo estático e unificado do conhecimento] visualizará a resolução de problemas como os meios para desenvolver e empregar as estratégias e os processos matemáticos, e para descobrir as verdades e as estruturas da Matemática. Um professor com filosofia/visão falibilista da Matemática [visão de Matemática como um campo de criação humana em grande e constante expansão] externalizará a resolução de problemas como uma pedagogia apropriada para empregar em sala de aula. Para Ernest (1991), esta filosofia/visão é vista como um processo socialmente mediado de elaborar problemas e de construir soluções. Para isso exige, dos sujeitos do processo, discussão para a negociação de significados/sentidos, estratégias de resolução e provas.

Gómez Chacón (2003) ao examinar a influência de afetos na aprendizagem de Matemática destacou a existência de quatro eixos distintos de crenças em educação matemática: (1) crenças sobre Matemática, (2) crenças sobre a aprendizagem de Matemática, (3) crenças sobre si mesmo como aprendiz de Matemática e (4) crenças sobre o contexto social ao qual alunos e professores pertencem. Dessa forma, a literatura estudada nos permite enfatizar que existe uma relação entre afeto e cognição, e que esta relação influencia na maneira de pensar, atuar e agir do docente em relação à Matemática e seu processo pedagógico. Sendo assim, através da forma como os professores externalizam (A) a sua relação com a Matemática, (B) a forma como planejam tarefas de ensino, e (C) a maneira como refletem sobre a Matemática e seu processo pedagógico poderemos compreender pensamentos e decisões deles em aulas. Ou seja, poderemos compreender a relação dos professores com a Matemática e alguns aspectos do domínio afetivo deles que influenciam ou não em seu comportamento para trabalhar com resolução de problemas. Entretanto, constatamos, a partir dos estudos de Silva (2009) e Zanon (2011), que estas ideias de Ernest (1991; 1988), como visões Matemáticas distintas e separadas, podem nem sempre ser isoladas, pois, pode acontecer que professores expressem mais do que uma visão de Matemática em sua prática profissional. Portanto precisamos ser cautelosos quando trabalhamos com outros professores ao procurar interpretar suas visões para não rotular ninguém apressadamente. 
Polya (1978/1945) iniciou uma discussão acerca da resolução de problemas e nos lembra que o professor precisa ajudar o aluno de maneira discreta e natural, na forma de pistas e indicações que o levem a pensar, para não tirar dele o sabor da descoberta e de forma que a ele caiba uma boa parte do trabalho. Os estudos de Polya (1978/1945) e outros pesquisadores (BRASIL, 1997; DINIZ, 2001; ONUCHIC, ALLEVATO, 2004; SANTOS, 1994, 1997; SANTOS-WAGNER, 2008) levaram a temática de resolução de problemas a ter papel de destaque dentro do currículo e ensino de Matemática em documentos oficiais e em pesquisas. Assim, corroboramos com Santos (1997) quando enfatiza que a coordenação de experiências anteriores, o conhecimento e a intuição são processos mentais envolvidos em uma atividade bem sucedida de resolução de problemas. Sendo a intuição uma tentativa de encontrar um método para resolver a situação cuja solução é desconhecida. Aponta também que a experiência, fatores afetivos e cognitivos estão envolvidos no processo de resolução de problemas.

\section{CONTEXTO DA PESQUISA}

A partir de uma pesquisa qualitativa (FIORENTINI; LORENZATO, 2007) conduzimos oficinas de formação continuada com professoras em exercício. Inicialmente vislumbramos uma proposta para professores; no entanto, era de nosso conhecimento que tanto as políticas de formação continuada como os programas delas oriundos pouco se valem das necessidades reais dos professores em formação. Assim, na segunda oficina, notamos que as professoras envolver-se-iam mais se as oficinas fossem planejadas e implementadas junto com elas. Dessa forma, alteramos nossa ideia inicial e mudamos o rumo das ações formativas. Passamos, então, a organizar as oficinas junto com as professoras, a partir de questões que diziam ser relevantes para elas em termos de ensino, aprendizagem e avaliação em matemática nos anos iniciais.

Essas oficinas ocorreram na Secretaria Municipal de Educação de Castelo/ES, semanalmente 
às quartas-feiras, de $18 \mathrm{~h}$ às $21 \mathrm{~h}$. Foram realizados 15 encontros de junho a novembro de 2010, com duração média de 3 horas cada. Dentre todos os encontros de oficinas, alguns foram concebidos para compreender os pensamentos sobre Matemática e resolução de problemas das professoras que ensinavam Matemática em escolas da zona rural deste município.

Dessa forma, os instrumentos e tarefas foram construídos para possibilitar que elas notassem de forma consciente a relação afetiva delas com a Matemática a partir das informações que relatavam. Pensamos que estes instrumentos propiciariam a tomada de consciência da relação emocional das professoras com a Matemática (SANTOS, 1994). Essa experiência de tomada de consciência seria um "instrumento de controle pessoal, um poderoso mediador nas relações com os outros e um elemento chave da autorregulação da aprendizagem em sala de aula" (GÓMEZ CHACÓN, 2003, p. 24). Assim, os instrumentos foram desenvolvidos com base no uso de metáforas (CHAPMAN, 2006) relacionadas ao campo cognitivo e afetivo (GÓMEZ CHACÓN, 2003). Chapman (2006) afirma que o uso de metáforas permite acessar indiretamente os pensamentos dos professores a respeito de suas práticas. De acordo com Gómez Chacón (2003), ao estudar o campo afetivo (crenças, atitudes e emoções) temos um panorama sobre quem são os professores em termos do comportamento em Matemática.

\section{RESULTADOS E DISCUSSÃO}

A investigação que fundamenta este artigo agrupou as professoras participantes do estudo em grupos de acordo com a experiência docente de cada uma. Assim, foram organizados 05 grupos distintos: (a) de 01 mês até 11 meses de experiência; (b) de 01 a 03 anos; (c) de 04 a 06 anos; (d) de 07 a 10 anos; (e) de 11 a 18 anos; (f) de 19 a 30 anos; (g) de 31 a 41 anos de experiência. Escolhemos três professoras: $P_{4}$ do grupo (a), $P_{20}$ do (d) e $P_{23}$ do (f) para analisarmos a relação entre a visão de Matemática e a visão de resolução de problemas que identificamos durante as oficinas e que confirmamos e/ou confrontamos com as tarefas 
matemáticas de aula que elas nos apresentavam em diversos momentos nas oficinas.

A professora $\mathrm{P}_{4}$ estava em início de docência. Havia concluído a graduação em Pedagogia e não possuía experiência anterior com a regência de classe. Durante as oficinas observava as demais colegas com vistas a construir um repertório metodológico a partir das experiências delas. A professora $\mathrm{P}_{20}$ encontrava-se preocupada com seu desenvolvimento profissional, uma vez que relatava já ter superado as inseguranças oriundas dos primeiros anos de docência; dizia possuir um bom repertório de experiências com vistas a decidir sobre os ritmos e os percursos de sua carreira, a fim de projetar o futuro de sua profissão (NÓVOA, 1995). A professora $P_{23}$ possuía experiência docente de cerca de 19 anos; instruiu-se inicialmente na escola normal, por meio de um modelo de educação mais tradicional e assim demonstrou ter um tipo bem peculiar de visão de mundo, de educação, de currículo. Nas oficinas, dialogava com as colegas e expunha ideias com zelo e cautela. Era temerosa ao expressar o que não sabia. Quando indagadas sobre "O que eu gostaria de dizer sobre a Matemática é...", elas relataram

Algo sem prazer [...] tenho que saber por saber, sem lógica [...] eu gostaria de entender os "porquês" e os "para quês", para que o meu aprendizado se tornasse prazeroso $\left(\mathrm{P}_{4}\right.$ em 23/06/2010).

Uma caixinha de surpresa. Cada dia aprendemos alguma coisa. A Matemática é a realidade que vivemos dia a dia [...] mesmo sendo um bloqueio, que ela não é tão difícil $\left(P_{20}\right.$ em 23/06/2010).

A Matemática está presente no dia a dia [...] Uma ciência que precisa ser pensada para chegar aos resultados. Que ela não é tão difícil, basta ter paciência e estudo para aprender. Ela já faz parte da nossa vida e precisa ser entendida ( $P_{23}$ em 23/06/2010).

Ao solicitarmos que registrassem com um desenho e com a primeira palavra que viesse à mente o que sentiam quando ouviam falar em Matemática, traduziram seus pensamentos e sentimentos nas figuras apresentadas no quadro abaixo. 
Quadro 1. Visão de matemática de $\mathrm{P}_{4}, \mathrm{P}_{20}$ e $\mathrm{P}_{23}$, respectivamente em dois momentos.

\begin{tabular}{|c|c|}
\hline $\begin{array}{l}\text { VISÃO DE MATEMÁTICA INICIAL } \\
\text { (OFICINA } 1 \text { EM 23/06/2010) }\end{array}$ & $\begin{array}{l}\text { VISÃO DE MATEMÁTICA APÓS AS OFICINAS } \\
\text { (OFICINA } 15 \text { EM 10/11/2010) }\end{array}$ \\
\hline $\begin{array}{c}\text { Para a professora } \mathrm{P}_{4} \text { a Matemática é um horror. Ela a } \\
\text { percebe como algo proibido. Assim, acreditamos que } \\
\text { ela nos indica que a Matemática é algo que devemos } \\
\text { passar por ela, uma vez que não é permitido se } \\
\text { relacionar com a mesma e que se constitui como algo } \\
\text { que não lhe causa prazer. }\end{array}$ & $\begin{array}{l}\text { Figura 2. Desenho de } \mathrm{P}_{4} \text { para expressar seu } \\
\text { pensamento e sentimento sobre Matemática. } \\
\text { - Matemática } \\
\text { Parece que a professora modificou sua crença inicial } \\
\text { sobre Matemática. Nesta ilustração notamos que ela } \\
\text { passou a compreender que a Matemática é um } \\
\text { aprendizado. E ao aprendê-la, as ideias se tornam } \\
\text { mais claras para quem aprende. }\end{array}$ \\
\hline $\begin{array}{l}\text { Figura 3. Desenho de } \mathrm{P}_{20} \text { para expressar seu } \\
\text { pensamento e sentimento sobre Matemática. } \\
\text { Patercebemos que a relação desta professora com a } \\
\text { Matemática é de desespero. Algo com o qual se sente } \\
\text { amedrontada e com muita angústia. Aponta-nos } \\
\text { indícios de que sua relação com a Matemática é } \\
\text { marcada por experiências negativas. }\end{array}$ & $\begin{array}{l}\text { Diferentemente da oficina } 1 \text {, na oficina } 15 \text { esta } \\
\text { professora aponta indícios de que a Matemática pode } \\
\text { ser uma luz que se acende quando se consegue } \\
\text { compreender seus conceitos. Que a Matemática pode } \\
\text { ser aprendida. Assim sendo, apresentou uma aparente } \\
\text { mudança na forma de ver e conceber a Matemática. }\end{array}$ \\
\hline $\begin{array}{l}\text { Figura 5. Desenho de } \mathrm{P}_{23} \text { para expressar seu } \\
\text { pensamento e sentimento sobre Matemática. } \\
\text { Para esta professora, a Matemática } \\
\text { um desafio que é possível de ser superado através de } \\
\text { estudos realizados pelo professor. Percebemos com a } \\
\text { figura do caderno, que a Matemática é uma disciplina } \\
\text { aprendida na escola por meio de registros escritos. }\end{array}$ & $\begin{array}{l}\text { Figura 6. Desenho de } \mathrm{P}_{23} \text { para expressar seu } \\
\text { pensamento e sentimento sobre Matemática. } \\
\text { mactématica } \\
\text { Na oficina } 15 \text { percebemos que esta professora } \\
\text { associou a Matemática a números. Esta associação } \\
\text { aponta indícios de que as oficinas de números } \\
\text { marcaram bastante essa professora e que as } \\
\text { aprendizagens construídas sobre esses conceitos } \\
\text { foram significativas. }\end{array}$ \\
\hline
\end{tabular}

Fonte: Acervo próprio. 
É notório que as professoras $\mathrm{P}_{4}$ e $\mathrm{P}_{20}$ chegaram às oficinas apontando indícios de crenças negativas sobre aprendizagem de Matemática e $P_{23}$ tinha uma visão positiva e de possibilidades de aprender, conforme descritos por Gómez Chacón (2003). Esse tipo de crença negativa, como a exibida por $\mathrm{P}_{4}$ e $\mathrm{P}_{20}$ e externalizada em seus desenhos e falas iniciais, é gerada no aluno quando a situação de aprendizagem à qual é exposto não corresponde às suas expectativas. Ou seja, quando o aluno tem dificuldades de aprender e entender os conceitos estudados, e assim se produz grande insatisfação em sua reação frente à Matemática, tanto afetiva quanto cognitiva, que interfere na sua motivação para aprender. Como já mencionamos, Ernest (1988) destacou a importância de conhecer as crenças e concepções dos professores sobre a natureza e sobre o processo pedagógico da Matemática quando se quer ensiná-la sob a perspectiva de resolução de problemas.

Thompson (1997/1984) observou o comportamento de professores a partir de diferentes abordagens didáticas. Em suas análises, reafirma as visões de Ernest sobre a Matemática e seu ensino. Assim sendo, de acordo com os registros e participação das professoras nos 15 encontros de oficinas, podemos dizer que $\mathrm{P}_{4}$ e $\mathrm{P}_{20}$ apontaram indícios de possuir uma visão de Matemática como um instrumento útil para se atingir um fim, ou seja, uma visão utilitarista. Nessa visão, a Matemática era entendida por elas como um conjunto de fatos, regras e procedimentos independentes, porém utilitários. Notamos, a partir dos registros e de sua participação nos 15 encontros de oficinas, que a professora $\mathrm{P}_{23}$ apontou indícios de possuir uma visão com aspectos tanto da visão utilitária quanto da visão platônica de matemática, na qual ela é vista como um corpo estático e unificado de conhecimentos. Vejamos no quadro a seguir: 
Quadro 2. Pensamentos e sentimentos, crença e concepção e visão de matemática, verbalizados pelas professoras nas oficinas 1 e 15.

\begin{tabular}{|c|c|c|c|c|c|c|}
\hline \multirow{2}{*}{ 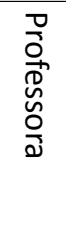 } & \multicolumn{3}{|c|}{ Oficina $1(23 / 06 / 2010)$} & \multicolumn{3}{|c|}{ Oficina 15 (10/11/2010) } \\
\hline & $\begin{array}{l}\text { Pensamentos } \\
\text { e sentimentos }\end{array}$ & $\begin{array}{l}\text { Crença e concepção } \\
\text { delas sobre sua } \\
\text { capacidade de aprender } \\
\text { Matemática }\end{array}$ & $\begin{array}{l}\text { Visão } \\
\text { Inicial }\end{array}$ & $\begin{array}{l}\text { Pensamentos } \\
\text { e sentimentos }\end{array}$ & $\begin{array}{l}\text { Crença e concepção } \\
\text { delas sobre sua } \\
\text { capacidade de aprender } \\
\text { Matemática }\end{array}$ & $\begin{array}{l}\text { Visão } \\
\text { Final }\end{array}$ \\
\hline $\mathrm{P}_{4}$ & Horror & Medo, horror, & Utilitária & Luz & Algo possível de ser & Utilitária \\
\hline$P_{20}$ & Desespero & $\begin{array}{l}\text { desespero em aprender } \\
\text { Matemática. }\end{array}$ & & & a & \\
\hline \multicolumn{7}{|c|}{$\begin{array}{l}\text { Pareceu-nos que } P_{4} \text { e } P_{20} \text { começaram a sentir que elas tinham possibilidade de aprender, de enxergar alguma } \\
\text { coisa quanto ao seu aprendizado de matemática, clarear o conhecimento delas e isto talvez para elas } \\
\text { ensinarem melhor. Notamos que as oficinas causaram algum impacto nelas, pois trouxeram representações } \\
\text { que estavam passando de uma visão negativa para uma visão positiva de matemática. }\end{array}$} \\
\hline $\mathrm{P}_{23}$ & Desafio & $\begin{array}{l}\text { Pareceu-nos imparcial } \\
\text { quanto à aprendizagem } \\
\text { de matemática, } \\
\text { podendo ser algo } \\
\text { negativo ou positivo. }\end{array}$ & Platônica & Números & $\begin{array}{l}\text { Acredita que ela vai } \\
\text { melhorar a aprendizagem } \\
\text { dela. }\end{array}$ & Utilitária \\
\hline
\end{tabular}

Fonte: Acervo próprio.

Para compreendermos pensamentos das professoras sobre resolução de problemas, desenvolvemos junto com elas, a partir dos seus interesses em relação aos tópicos de matemática, 07 oficinas para tratar desse tema. Assim, a partir das informações coletadas e produzidas nessas oficinas investigamos seis temas emergentes: (1) a compreensão do significado dado pelas professoras à palavra problema; (2) alguns tipos de problemas que elas afirmavam conhecer e utilizar; (3) a compreensão delas acerca do que é uma atividade de resolução de problemas; (4) algumas estratégias que elas mencionavam usar em suas aulas para conduzir e auxiliar seus alunos em atividades de resolução de problemas; (5) a forma como elas diziam elaborar aulas sobre o tema; e (6) como elas mencionavam avaliar tais atividades. Porém, neste texto, enfocaremos apenas nos itens (1) e (3).

Com base nas respostas delas, notamos que entendiam problema como o surgimento de uma dúvida, de um desafio a ser solucionado através do pensamento, da análise e da reflexão. Pareceu-nos que (1) essa compreensão do significado dado pelas professoras à palavra problema foi semelhante ao descrito por Polya como ponto de partida (1978/1945). 
Externalizavam, também, mesmo que de forma tímida, algumas das estratégias que precisam ser exploradas em uma atividade de resolução de problemas (SANTOS, 1997). Destacamos que nesta etapa das oficinas, as professoras não possuíam conhecimentos formais sobre o conceito de problema, as estratégias e as fases de resolução de um problema.

As atividades de resolução de problemas podem ser usadas como uma estratégia metodológica para a construção de conhecimentos matemáticos. Assim, investigamos a respeito da (3) compreensão delas acerca do que é uma atividade de resolução de problemas. Notamos que $\mathrm{P}_{4}, \mathrm{P}_{20}$ e $\mathrm{P}_{23}$ entendiam uma atividade de resolução de problemas como uma tarefa que faz o aluno pensar, além de estimular o raciocínio lógico. 0 entendimento das professoras sobre o que é uma atividade de resolução de problemas estava associado à compreensão delas sobre o que é um problema. Exemplo disso pode ser visualizado no quadro 3. Notamos ainda que, mesmo sem possuir um conhecimento da literatura, as professoras se aproximaram das ideias de Santos (1997) ao destacar que uma atividade bem-sucedida de resolução de problemas envolve os processos mentais de coordenar experiências anteriores, conhecimento e intuição. Assim sendo, uma atividade de resolução de problemas mobiliza alguns conhecimentos, desencadeia a construção de outros e atribui significados às situações matemáticas. 
Quadro 3. Atividade de resolução de problema apresentada pela professora $\mathrm{P}_{4}$ nas oficinas de formação continuada e trabalhada com seus alunos.

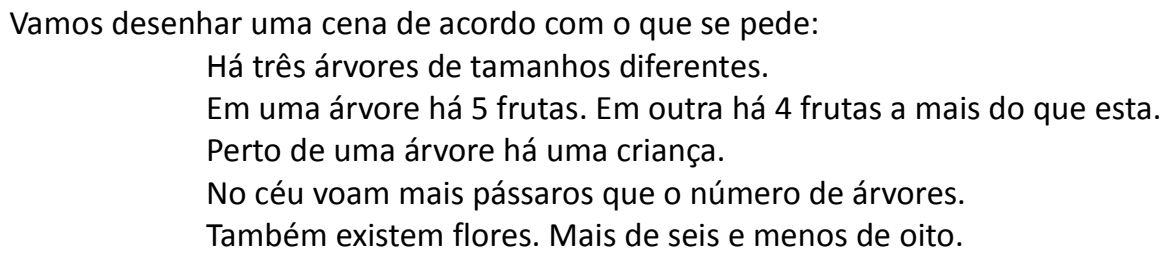

Fonte: Acervo próprio.

Figura 7. Resposta de aluno ao problema apresentado pela professora $\mathrm{P}_{4}$.

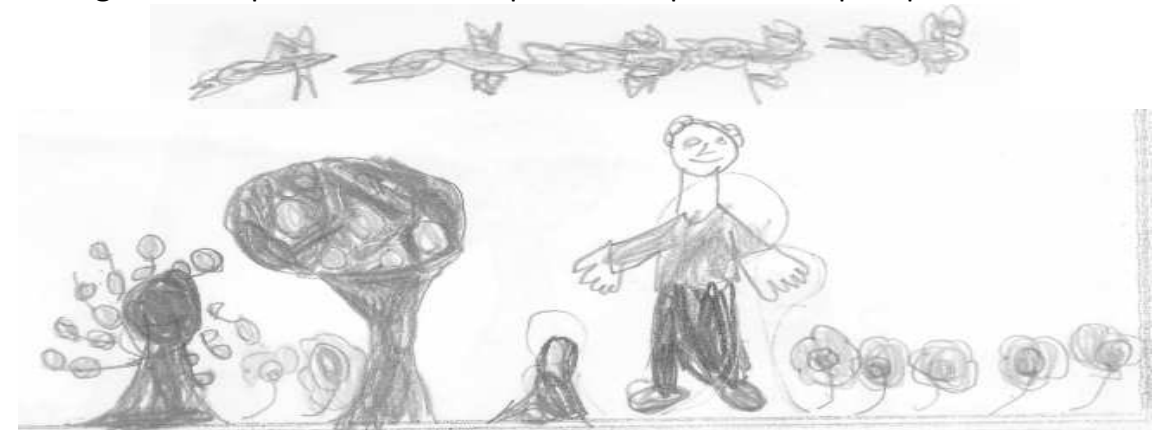

Fonte: Acervo próprio.

A professora $\mathrm{P}_{4}$ atuava em uma turma de 10 ano do Ensino Fundamental composta por 10 alunos de 6 anos de idade. Ela nos apresentou esta atividade de resolução de problemas na oficina 08 em 1ำ09/2010, dois meses após o início das oficinas e depois de vários momentos de estudo, análise e reflexão sobre o tema em questão. A professora nos apresentou também a resposta de 08 crianças a esta tarefa. No plano de aula que elaborou, descreveu que preparou a tarefa para ser desenvolvida durante três aulas de 50 minutos. Apresentou como objetivo para esta aula que seus alunos conseguissem "relacionar números e quantidades e descrever tamanhos diferentes". Pontuou também que durante o processo de resolução pretendia identificar quais dificuldades os alunos teriam para encontrar a solução para o problema. A professora nomeou de "ação didática" os procedimentos que ela usaria para que os alunos compreendessem e executassem a tarefa proposta. Assim descreveu:

No primeiro momento ir lendo com os alunos e esperar que façam o comando; no segundo momento observar o que fizeram e corrigir no quadro as dificuldades que encontraram (Professora $\mathrm{P}_{4}$, em 01/09/2010). 
A professora nos relatou que entregou a tarefa aos alunos, orientou que registrassem o nome deles, a data e identificassem a turma. Depois seguiu lendo cada frase do problema. Ao terminar a leitura, aguardava os alunos registrarem a compreensão deles sobre o que era solicitado na mesma. Percebemos que a professora advogou certa liberdade para as crianças representarem e expressarem através das representações por registros de imagens, desenhos, os conhecimentos matemáticos de número, quantidade e medida.

No entanto, observamos que foi uma liberdade orientada pela professora que demonstrou um conhecimento sobre o trabalho que estava desenvolvendo com a resolução de problemas como metodologia para o ensino, aprendizagem e avaliação em Matemática, para posteriormente intervir, no quadro, como ela propôs, caso fosse necessário, auxiliando na organização do conhecimento matemático pelos alunos. Pareceu-nos que a professora foi incorporando os estudos e discussões das oficinas em sua prática docente, até mesmo superando sua visão de Matemática como horror (Quadro 1, Figura 1) para uma visão de Matemática como luz (Quadro 1, Figura 2) como possibilidade de aprendizado (GÓMEZ CHACÓN, 2003). Essa outra forma de ver e conceber a Matemática apresentada pela professora $\mathrm{P}_{4}$ corrobora com Ernest (1991), quando ele aponta que a visão de Matemática que o professor possuiu influencia na forma como ele exterioriza a resolução de problemas em sala de aula.

Analisando o problema descrito pela professora, vemos que o aluno não precisava identificar a quantidade registrando-a por meio de um algarismo. No entanto, ele, o aluno, precisava compreender e identificar a quantidade que era solicitada pela professora durante a leitura (pois eles ainda não eram alfabetizados), construir padrões de associação numérica mentalmente e expressar a quantidade ou a medida (grande, médio, pequeno) por meio de uma cena, de um desenho que representava o seu "eu" criança, ou seja, uma forma própria de expressão pictórica. Enfim, podemos dizer que o aluno cuja solução aqui é apresentada compreende a noção numérica bem como a de medida (grande, médio, pequeno) tais como 
são discutidas por Lorenzato (2008) e Smole (2003).

Não ficou evidente se durante o desenvolvimento da tarefa houve um momento de escuta dos alunos, no qual a professora pudesse dialogar com eles sobre suas representações e compreensões. Pelas resoluções das crianças, vemos que a maioria delas conseguiu representar a cena usando o desenho.

Não houve escrita de algarismos que representassem quantidades, nem incorporações de conhecimentos de outros assuntos, para além da Matemática, à prática de sala de aula durante o desenvolvimento dessa tarefa. Talvez pelo fato desta professora ainda ser recémformada, estar nos primeiros anos da docência e ainda construindo um repertório de conhecimento para ensinar Matemática, conforme aponta Shulmam (1986; 1987). 
Figura 8. Atividades de resolução de problema apresentada pela professora $P_{20}$ nas oficinas de formação continuada com respostas de aluno.

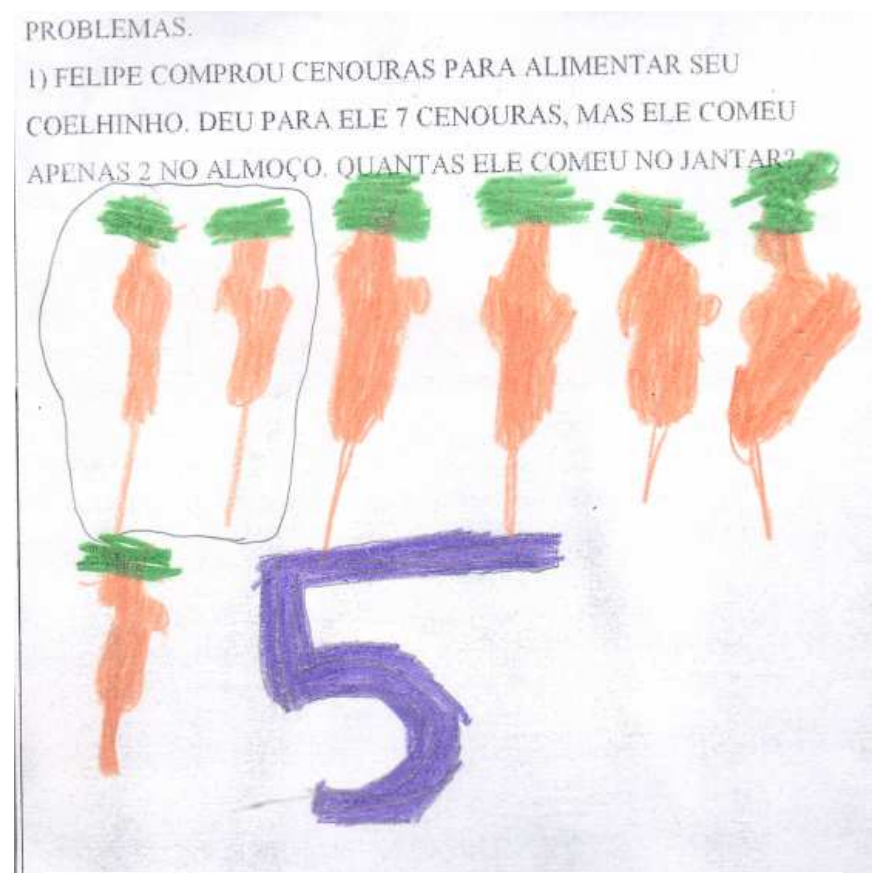

PROBLEMAS

2) EM UMA ARVORE HAVIA S PASSARINHOS. LUCAS ATIROU PEDRAS E MATOU 3 PASSARINHOS QUANTOS PASSARINHOS SOBRARAM NA ARVORE? '

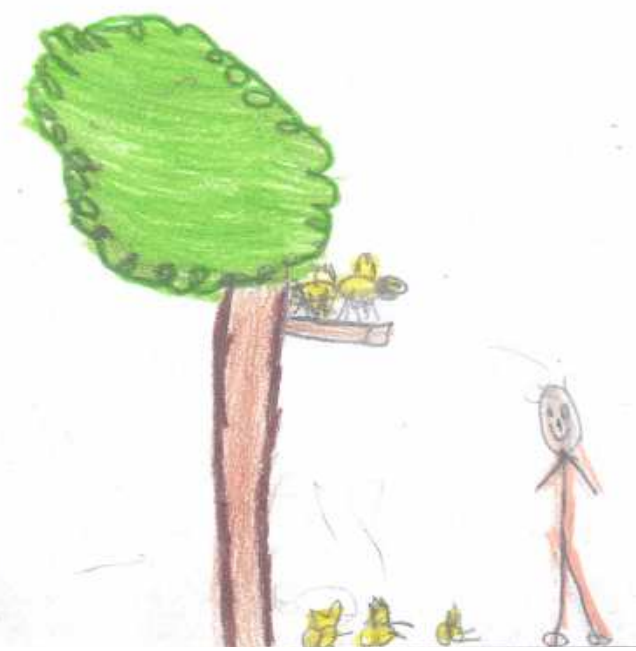

Fonte: Acervo próprio.

Assim como a professora $\mathrm{P}_{4}, \mathrm{P}_{20}$ também lecionava em uma turma de 1 o ano do Ensino Fundamental, esta composta por 11 alunos de 6 anos de idade. Ela também nos apresentou esta atividade de resolução de problemas na oficina 08 no dia 1ำ09/2010, dois meses após 
o início das oficinas e depois de vários momentos de estudo, análise e reflexão sobre o tema em questão. Junto aos problemas propostos, ela mostrou a resolução dos seus 11 alunos. Ela não havia redigido um plano de aula, no entanto descreveu os procedimentos que usou para o desenvolvimento da tarefa que elaborou.

Relatou que pensou na tarefa para ser desenvolvida de $7 \mathrm{~h}$ as $9 \mathrm{~h} 20$, quando se iniciava o recreio. Pretendia que os alunos identificassem as quantidades apresentadas nos problemas e operassem com elas. A professora nos relatou que entregou a tarefa aos alunos, orientou que registrassem o nome deles, a data e identificassem a professora. Como metodologia, foi lendo os problemas e dando ênfase em palavras que considerava que ajudaria na resolução pelos alunos. Por exemplo, na Figura 8, problema 1, enfatizou "deu para ele 7 cenouras, mas ele comeu, oh... comeu, 2 cenouras... e aí, quantas sobrou para o jantar?". Observamos que ela já ia fornecendo pistas aos alunos sobre os procedimentos de resolução. E assim também fez para o problema 2. Ressaltou que, ao elaborar os problemas, usou situações do cotidiano das crianças para que elas tivessem mais interesse e vontade de resolver. Essa é a ideia de subtração que as crianças já têm quase que intuitivamente: o problema apresenta uma situação com uma quantidade inicial fixa, acontece algum movimento (retirar, comer, guardar, separar) e no final da situação, pergunta-se para criança "com que quantidade ficou?" quer saber o que restou, o que sobrou, o que ficou no final. A criança acompanha a historinha, o contexto que é apresentado, e ela vai pensando nos fatos que aconteceram para chegar à ideia do que restou. São raciocínios que fazem parte do pensamento infantil. Também vemos que ambos os problemas são situações associadas à ideia de transformação, mudança (SILVA, 2009) na quantidade inicial para verificar com qual quantidade a criança ficou ao final.

Em relação as estratégias de resolução apresentadas pelos alunos, notamos que primeiramente os alunos representaram a cena com ilustrações que mostram a compreensão deles acerca do problema proposto; em seguida, a maioria deles fez um registro numérico da operação, expressando, assim, numericamente, os resultados 
encontrados; alguns ainda construíram o cenário de representação da situação informando o total de cenouras ou de passarinhos, não escrevendo a operação matemática formal, mas "circulando", por exemplo, o número de cenouras que o coelho comeu, como no caso apresentado pelo problema 1, Figura 8 , e registrando numericamente o resultado; essa forma de resolução também apareceu no problema dos passarinhos. Os alunos de $P_{20}$ também não eram alfabetizados, mas compreenderam o contexto do problema a partir da leitura feita pela professora. Diferentemente dos alunos da professora $P_{4}$, os alunos de $P_{20}$, ilustraram a cena e incorporaram o registro dos algarismos componentes da sentença matemática que resolveria o problema proposto.

Vemos que esta professora também procurou incorporar à sua prática cotidiana de sala de aula as discussões e reflexões provenientes das oficinas. Observamos também que ela via a Matemática como algo desesperador (Quadro 1, Figura 3) e que foi apontando indícios de superação dessa visão de Matemática ao longo das oficinas, passando a vê-la como luz (Quadro 1, Figura 4), como possibilidade de aprendizado. As representações dessa professora apontam que a visão de Matemática está passando de algo negativo, ruim, para algo positivo, possível, incidindo em sua capacidade para aprender Matemática (GÓMEZ CHACÓN, 2003) e na forma como concebe e usa a resolução de problemas em sala de aula (ERNEST, 1991). 
FORMAÇÃO INICIAL E CONTINUADA DE PROFESSORES DA EDUCAÇÃO BÁSICA

Figura 9. Atividade de resolução de problema apresentada pela professora $P_{23}$ nas oficinas de formação continuada com respostas de aluno.

NA FAZENDA DO SENHOR JOAQUIM HÁ VÁRIOS ANIMAIS. VEJA O QUADRO

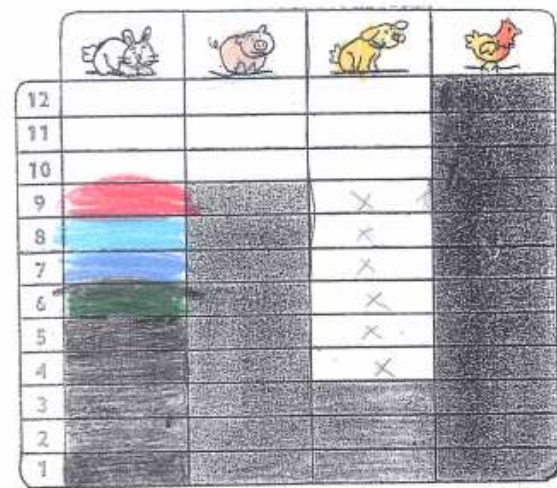

DE ACORDO COM O QUADRO, RESPONDA

A) O SENHOR JOAQUIM TEM, NA FAZENDA

- COELHOS

- porcos

- CÃES

- gaitnha 12

B) QUE ANIMAL O SENFFOR JOAOUTM TFM EM MATOR QUANTTEADE'

GMLIN 1 H

C) QUANTOS PORCOS O SENHOR JOAQUIM TEM AMIAS QUE CÃES? MARQUE COM UM (X) NA TABELA.

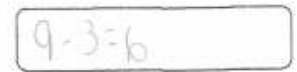

D) SE O SENHOR JOAQUTM COLOCAR COELHOS E CÃES JUNTOS, QUANTOS ANIMAIS TERÁ? ILUSTRE.
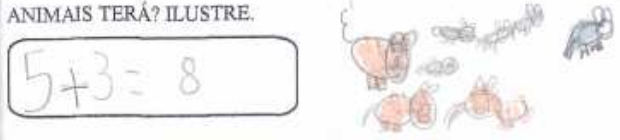

E) SE O SENHOR JOAQUTM DER 3 GALINHAS AO SEU VIZINHO, FICARÁ COM QUANTAS GALINHAS?

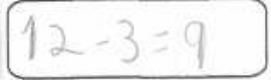

F) SE O SENHOR JOAQUTM GANHAR MAIS 4 COELHOS, COM QUANTOS COELHOS FICARÁ? $\| / / / \mathrm{I} / / / /$

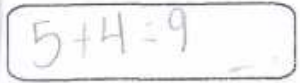

G) QUANTOS ANMAIS HA NO TOT AL? REGISTRE, COMO VOCÊ CHEGOU A ESTÁ CONCLUSÃO?

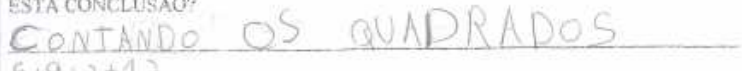
$5+9+3+12$

Fonte: Acervo próprio. 
A professora $\mathrm{P}_{23}$ lecionava numa turma de 10 ano do Ensino Fundamental composta por 06 alunos com 06 anos de idade. A atividade de resolução de problemas descrita na Figura 9, também foi apresentada na oficina 08 em 01/09/2010, dois meses após o início das oficinas, depois de vários momentos de estudo, análise e reflexão sobre o tema em questão. Assim, como $\mathrm{P}_{4}$ e $\mathrm{P}_{20}$, a professora $\mathrm{P}_{23}$ apresentou também a resolução dos seus alunos. No plano de aula desta professora encontramos um objetivo geral "desenvolver a capacidade do aluno quanto ao raciocínio lógico e interpretação de dados" e os objetivos específicos "observar o gráfico e analisar os dados apresentados; relacionar as quantidades existentes em cada coluna diferenciando quanto à adição e à subtração; e, associar os diversos itens existentes quanto às interpretações feitas para obter os resultados". Como metodologia propôs a distribuição da atividade xerografada, a leitura oral da atividade, a resolução das questões propostas e a correção da tarefa no quadro. Não informou sobre o tempo de duração da tarefa.

Durante a oficina quando os problemas foram compartilhados no grupo com as demais professoras, $P_{23}$ relatou que elaborou a atividades de resolução de problemas buscando incorporar o tema animais que estava sendo discutido em Ciências, ou seja, disse que buscou estruturar uma tarefa interdisciplinar. Ela mencionou que entregou a tarefa aos alunos, orientou que registrassem o nome da escola, o nome deles e a data. Descreveu que foi lendo junto com os alunos as situações apresentadas e que em seguida aguardava que eles resolvessem. Depois, ia para o quadro e resolvia a questão a partir das construções dos alunos. Assim, expunha as formas de registro pictórico, numérico e escrito fazendo o uso da língua materna. Ela pontuou que o problema foi adaptado de um livro de atividades para o ano em que lecionava e que durante a resolução os alunos apontaram dificuldades em compreender, "é mais ou é menos, tia?".

A esse respeito, Muniz (2009) destaca que vários podem ser os motivos que levam os alunos a fazerem essa indesejada pergunta. São eles:

- Dificuldade de interpretação do texto que constitui o enunciado;

- Operações ensinadas de forma estanque, uma a uma, sem uma articulação 
interna entre elas;

- Falta de significado da situação para o aluno, levando-o a não identificar os conceitos que a mesma implica;

- Ausência de autonomia intelectual e moral do aluno que foi levado a buscar, no adulto, o suporte para validação de suas ações cognitivas;

- Baixa autoestima e insuficiente autoconfiança, uma vez que o aluno é submetido a um ambiente educativo em que o erro é fonte geradora de punições. A possibilidade de punição leva o aluno a não ação, fazendo com que fique aguardando uma pista do professor para mostrar o caminho certo a ser percorrido;

- Enunciado não evidencia apenas dois números a serem diretamente operados. Afinal, desde cedo, o aluno aprende que resolver um problema é pegar/utilizar os dois números presentes no enunciado e operá-los: resolver o problema é somente descobrir qual a operação a ser realizada entre os dois números. Há maior dificuldade quando o aluno precisa selecionar os dados necessários entre os diversos dados pelo enunciado ou mesmo quando um deles se apresenta de forma escrita na língua materna e não em indu-arábico;

- Hábito de encontrar, no texto, palavras que conduzem de forma absoluta a determinada operação aritmética, tais como: “juntos" é para somar, "retirou" é para subtrair, "repartir" é para dividir e assim por diante (p. 101 $-102)$.

Para a professora há relação entre os argumentos de Muniz (2009) e a vivência dela em sala de aula. Nossas experiências como professoras nos permitem dizer que as operações que envolvem a ideia de comparação são muito mais complexas e exigem que o professor explore inúmeras situações em sala de aula com o intuito de auxiliar o aluno na organização do seu conhecimento matemático. Em relação às estratégias de resolução apresentadas pelos alunos, percebemos que foram muito semelhantes àquela apresentada na Figura 9. Como esta professora já está na docência há mais tempo que $\mathrm{P}_{4}$ e $\mathrm{P}_{20}$, nos pareceu que a atividade trazida por ela se apresentava de maneira mais elaborada envolvendo as 
representações por imagem, o registro numérico formal e atividade interdisciplinar com ciência, apontando também uma motivação dela em ampliar o conhecimento compartilhado com seus alunos.

Notamos que $\mathrm{P}_{23}$ também procurou incorporar à sua prática cotidiana de sala de aula as discussões e reflexões provenientes das oficinas. Observamos também que ela via a Matemática como um desafio (Quadro 1, Figura 5) e que não aponta uma relação nem positiva, nem negativa com a Matemática. Já ao final das oficinas, a professora relacionou sua visão de Matemática a números (Quadro 1, Figura 6), talvez porque as oficinas de números tenham sido significativas para ela ou que houve reflexão em termos de reconhecimento de que seu conhecimento sobre o assunto precisava ser melhorado. Assim, suas representações apontam indícios sobre sua vontade para aprender Matemática (GÓMEZ CHACÓN, 2003) e sobre a forma como concebe e usa a resolução de problemas em sala de aula (ERNEST, 1991).

É fato que as respostas das professoras foram determinadas pela visão de Matemática que cada uma possuía (ERNEST, 1988) e pela crença sobre si mesmas enquanto aprendizes de Matemática (GÓMEZ CHACÓN, 2003). Essa crença a respeito de si enquanto aprendizes de Matemática e a visão de Matemática foi construída a partir das experiências vividas como alunas da Educação Básica, na formação inicial e em atividades de formação continuada até o momento. Conhecermos o modo como as professoras planejavam e ministravam aulas de resolução de problemas nos auxiliou a conduzir alguns momentos de reflexão colaborativa. Propusemos um trabalho de reflexão e discussão sobre a metodologia de ensino de Matemática através da resolução de problemas, o estudo dos conceitos de problemas, tipos de problemas e características, e as fases da resolução de problemas segundo Polya (1978/1945). 


\section{CONSIDERAÇÕES FINAIS}

Retornemos aos nossos dois questionamentos neste texto: (1) Que correlações identificamos entre visões de Matemática e de resolução de problemas relatadas por professoras que ensinam Matemática em oficinas de formação continuada? e (2) Como observamos que essas visões interferem/influenciam mutuamente os processos de ensinar, aprender e avaliar em Matemática? Em nossa busca por respostas a estes questionamentos identificamos que as correlações estão na interferência/influência que a visão de Matemática exerce sobre a visão de resolução de problemas. Isto foi evidenciado nos argumentos e na literatura, principalmente Ernest (1991). Assim, ambas as questões estão imbricadas quando pensadas no processo de ensinar, aprender e avaliar em matemática e não podem ser respondidas isoladamente. É importante ressaltar que, pareceu-nos evidente, a resolução de problemas é entendida de forma distinta por professoras diferentes, de acordo com suas visões e suas experiências anteriores. E precisamos pensar nas experiências delas tanto enquanto alunas como as experiências que têm enquanto professoras que ensinam Matemática.

Em linhas gerais percebemos que, independentemente da experiência docente das professoras, era comum a todas algumas dúvidas sobre conteúdos específicos de Matemática e consequentemente sobre como ensinar os mesmos. Elas apresentaram dificuldade de conhecimento de conteúdo de matéria específica e de conhecimento pedagógico de conteúdo, ou conhecimento de como ensinar Matemática, principalmente sobre o sistema de numeração decimal, as quatro operações e resolução de problemas. Estes conhecimentos segundo Shulman (1986; 1987), referem-se aos conhecimentos específicos de uma área e aos conhecimentos pedagógicos de conhecimentos específicos. Constatamos que estes conteúdos, o sistema de numeração decimal, as quatro operações e resolução de problemas, são priorizados pelas professoras que ensinam Matemática nos anos iniciais do Ensino Fundamental. Elas priorizam estes assuntos porque estes aparecem nos currículos escolares e nos livros didáticos adotados nas escolas. Esta evidência também pode ser notada em Silva (2009) e em Mandarino (2009). Diante da dificuldade de conhecimento sobre os conteúdos mencionados, identificamos, ainda, durante fases das oficinas que as 
professoras demonstravam a forma como os ensinavam, que elas também possuíam dificuldades em lecionar tais temas. Como seu conhecimento de conteúdo era limitado, não conseguiam combinar adequadamente o conteúdo com os procedimentos metodológicos, conhecimentos que, segundo Shulman (1986; 1987), são necessários e típicos de um professor ao ensinar determinado conteúdo.

Nesse sentido, entendemos que o ensino acontece de forma adequada quando há vinculação entre a experiência construída ao longo da docência, destacada por Lorenzato (2008) e os conhecimentos de conteúdo e de metodologias de ensino, conforme apresentado por Shulman (1986; 1987). Porque o professor precisa conhecer o conteúdo e os métodos de ensino relacionados ao que vai ensinar, pois não é possível ensinar sem conhecer. Sabemos, portanto, que se um professor não possui conhecimento de conteúdo específico, também terá dificuldade de conhecimento pedagógico de conteúdo e terá dificuldades de relacionar estes conhecimentos, geralmente incipientes, com os outros conhecimentos de didática, de currículo, de contextos e de valores e fins da educação.

Por isso, construímos nas oficinas um espaço de respeito mútuo e valorização daquilo que cada professora trazia consigo. Dessa forma, mesmo que elas não dominassem o conteúdo, era-nos possível mostrar e discutir com cada uma suas dificuldades e limitações para aprender e ensinar Matemática. Com o passar do tempo, as professoras tornaram-se mais confiantes em nossas ideias, em si mesmas e nas outras, e, assim, conseguiam identificar os pontos em que precisavam melhorar. Por fim, notamos que as professoras $P_{4}, P_{20}$ e $P_{23}$ foram desequilibradas em termos cognitivos e afetivos e desenvolveram aspectos de seus processos metacognitivos, conforme destaca Santos (1994; 1997), porque passaram a questionar o que sabiam a respeito de conceitos matemáticos, como usavam e gerenciavam estes saberes, o que não sabiam e como poderiam aprender o que ainda desconheciam. Assim, a participação dessas professoras nas oficinas nos permitiu observar que a experiência docente vinculada ao conhecimento adquirido devem ser valorizados mediante a riqueza de situações didáticas vivenciada por elas (LORENZATO, 2008). 


\section{REFERÊNCIAS}

BRASIL. Parâmetros Curriculares Nacionais: matemática. Ministério da Educação, Secretaria de Educação Fundamental. Brasília: MEC/SEF, 1997.

CHAPMAN, O. Researching teaching qualitative techniques. Cadernos de Pesquisa em Educação, Vitória, PPGE/CE, UFES, v. 12, n. 23, p. 105-135, jan./jun. 2006.

DINIZ, M. I. Resolução de problemas e comunicação. Em: SMOLE, K. S.; DINIZ, M. I. (Org.). Ler, escrever e resolver problemas: habilidades básicas para aprender matemática. 1a ed. Porto Alegre: Artmed, 2001. p. 87-97.

ERNEST, P. Problem Solving: Its Assimilation to the Teacher's Perspective. Em: Mathematical Problem Solving and New Information Technologies - Research in Contexts of Practice. Editado por J. P. Ponte, J. F. Matos, J. M. Matos, D. Fernandes. NATO ASI Series, Vol. 89, 1991, p. $287-300$

The impact of beliefs on the teaching of mathematics. Em: C. Keitel, P. Damerow, A. Bishop, P. Gerdes (Ed.). Mathematics, education and society. Paris: United Nations Educational Scientific, 1988, p. 99-101.

FIORENTINI, D.; LORENZATO, S. Investigação em educação matemática: percursos teóricos e metodológicos. 2a ed. rev. Campinas, SP: Autores Associados, 2007.

GATTI, B. A; BARRETO, E. S. de Sá. Professores do Brasil: impasses e desafios. Brasília: UNESCO, 2009.

GÓMEZ CHACÓN, I. M. Matemática emocional: os afetos na aprendizagem matemática. Tradução de Daisy Vaz de Moraes. Porto Alegre: Artmed, 2003.

LORENZATO, S. Para aprender matemática. 2. ed. rev. Campinas, SP: Autores Associados, 2008.

MANDARINO, M. C. F. Que conteúdos da matemática escolar professores dos anos iniciais do Ensino Fundamental priorizam? Em: Guimarães, G.; Borba, R. (Org.). Reflexões sobre o ensino de matemática nos anos iniciais de escolarização. Recife: SBEM, 2009, 138 p. 29-48.

MUNIZ, C. A. Diversidade dos conceitos das operações e suas implicações nas resoluções de classes de situações. Em: Guimarães, G.; Borba, R. (Org.). Reflexões sobre o ensino de matemática nos anos iniciais de escolarização. Recife: SBEM, 2009, 138 p. 101-118.

NÓVOA, A. Formação de professores e profissão docente. Em: NÓVOA, A. (Org.). Os professores e a sua formação. Lisboa, Dom Quixote, 1995. p. 14-33.

ONUCHIC, L. de la R.; ALLEVATO, N. S. G. Novas reflexões sobre o ensino-aprendizagem de matemática através da resolução de problemas. Em: BICUDO, M. A. V.; BORBA, M. de C. 
(Org.). Educação matemática: pesquisa em movimento. São Paulo: Cortez, 2004, p. 213-231. POLYA, G. A arte de resolver problemas. Tradução de Heitor Lisboa de Araujo. Rio de Janeiro: Interciência, 1978. (Trabalho original publicado em inglês em 1945 com o Título "How to solve it".).

SANTOS, V. M. P. dos. Consciência metacognitiva de futuros professores primários numa disciplina de matemática e um exame de seu conhecimento, concepções consciência metacognitiva sobre frações. Série Documental Eventos, n. 4, 2a Parte, INEP, Brasília, n. 4, 2aㅡ parte, p. 1-20, 1994.

Avaliação de aprendizagem e raciocínio em matemática: métodos alternativos. Rio de Janeiro: Projeto Fundão, Instituto de Matemática da Universidade Federal do Rio de Janeiro, 1997.

SANTOS-WAGNER, V. M. P. dos. Resolução de problemas em matemática: uma abordagem no processo educativo. Boletim GEPEM, Rio de Janeiro, no 53, p. 43-74, jul./dez. 2008.

SHULMAN, Lee, S. Knowledge and teaching: foundations of the new reform. Harward Educational Review, v. 57, p. 1 - 22, 1987. Disponível em: http://ci.unlv.edu/files/Week3_Shulman_Knowledge_Teaching.pdf. Acesso em 09 nov. 2009.

Those who understand: knowledge growth in teaching. Stanford University, Educational Researcher, v. 15. n. 2, p. 4-14, 1986.

SILVA, S. A. F. da. Aprendizagens de professoras num grupo de estudos sobre matemática nas séries iniciais. 2009. 417f. Tese (Doutorado em Educação) - Programa de Pós-Graduação em Educação, Universidade Federal do Espírito Santo, Vitória.

SMOLE, K. C. S. A matemática na educação infantil: a teoria das inteligências múltiplas na prática escolar. Porto Alegre: Artmed, 2003.

THOMPSON, A. G. A relação entre concepções de matemática e de ensino de matemática de professores na prática pedagógica. Tradução de Gilberto F. A. de M., Tadeu O. G., Revisão de Maria Aparecida C. R. T. Moraes e Antônio Miguel. Zetetiké, CEMPEM - FE/UNICAMP, v. 5, no 8, p. 58-78, jul./dez. 1997. (Esse artigo de Thompson foi publicado originalmente em inglês na revista Educational Studies in Mathematics 15, 1984, p. 105-127).

ZANON, T. X. D. Formação continuada de professores que ensinam matemática: o que pensam e sentem sobre ensino, aprendizagem e avaliação. 2011. 300f. Dissertação de Mestrado (Mestrado em Educação) - Programa de Pós-Graduação em Educação, Universidade Federal do Espírito Santo, Vitória. 